\title{
Geospatial and Machine Learning Regression Techniques for Analyzing Food Access Impact on Health Issues in Sustainable Communities
}

\author{
Abrar Almalki ${ }^{1, *(D)}$, Balakrishna Gokaraju ${ }^{1}$, Nikhil Mehta ${ }^{2}$ and Daniel Adrian Doss ${ }^{3}$ (D) \\ 1 AI\&VI Lab from NCAT and Visualizations and Computing Advanced Research Center (ViCAR) North \\ Carolina Agriculture and Technical State University, 1601 East Market Street, Greensboro, NC 27411, USA; \\ bgokaraju@ncat.edu \\ 2 Department of Information Systems and Supply Chain Management, University of North Carolina at \\ Greensboro, Greensboro, NC 27402, USA; n_mehta@uncg.edu \\ 3 Interim Chair of Johnston Division of Business and Associate Professor of Cybersecurity, University of \\ Tennessee, Pulaski, TN 37478, USA; ddoss@tulane.edu \\ * Correspondence: aaalmalki@aggies.ncat.edu
}

Citation: Almalki, A.; Gokaraju, B.; Mehta, N.; Doss, D.A. Geospatial and Machine Learning Regression

Techniques for Analyzing Food Access Impact on Health Issues in Sustainable Communities. ISPRS Int. J. Geo-Inf. 2021, 10, 745.

https://doi.org/10.3390/ijgi10110745

Academic Editors: Wolfgang Kainz and Fazlay S. Faruque

Received: 28 July 2021

Accepted: 27 October 2021

Published: 3 November 2021

Publisher's Note: MDPI stays neutral with regard to jurisdictional claims in published maps and institutional affiliations.

Copyright: (c) 2021 by the authors. Licensee MDPI, Basel, Switzerland. This article is an open access article distributed under the terms and conditions of the Creative Commons Attribution (CC BY) license (https:// creativecommons.org/licenses/by/ $4.0 /)$.
Abstract: Food access is a major key component in food security, as it is every individual's right to proper access to a nutritious and affordable food supply. Low access to healthy food sources influences people's diet and activity habits. Guilford County in North Carolina has a high ranking in low food security and a high rate of health issues such as high blood pressure, high cholesterol, and obesity. Therefore, the primary objective of this study was to investigate the geospatial correlation between health issues and food access areas. The secondary objective was to quantitatively compare food access areas and heath issues' descriptive statistics. The tertiary objective was to compare several machine learning techniques and find the best model that fit health issues against various food access variables with the highest performance accuracy. In this study, we adopted a food-access perspective to show that communities that have residents who have equitable access to healthy food options are typically less vulnerable to health-related disasters. We propose a methodology to help policymakers lower the number of health issues in Guilford County by analyzing such issues via correlation with respect to food access. Specifically, we conducted a geographic information system mapping methodology to examine how access to healthy food options influenced health and mortality outcomes in one of the largest counties in the state of North Carolina. We created geospatial maps representing food deserts - areas with scarce access to nutritious food; food swamps-areas with more availability of unhealthy food options compared to healthy food options; and food oases-areas with a relatively higher availability of healthy food options than unhealthy options. Our results presented a positive correlation coefficient of $R^{2}=0.819$ among obesity and the independent variables of transportation access, and population. The correlation coefficient matrix analysis helped to identify a strong negative correlation between obesity and median income. Overall, this study offers valuable insights that can help health authorities develop preemptive preparedness for healthcare disasters.

Keywords: disaster preparedness; smart cities; sustainable cities; food desert; regression analysis

\section{Introduction}

City planning for sustainable communities requires equitable distribution of and access to healthy food options for inhabitants. This study examined the statistical association between food access on people's health and its connection to income and mobility access. The unbalanced distribution of food may have consequences concerning health and other factors. In this study, we examined these issues in Guilford County, North Carolina. Guilford County was ranked as the highest in food scarcity in North Carolina by the Food Research and Action Center in 2020 [1]. Since then, the county has worked to analyze the factors associated with food scarcity, studying the area's income, education, 
and poverty rates. To advance Guilford County from a scarcity condition to sustainable equal distribution condition, an estimate of the scarcity situation and an analysis of the geographic areas for improvements in food access were needed. A key objective of sustainable communities is to effectively manage the health issues of their inhabitants. The process included gauging food access distribution by spatial methods, analyzing potential factors, and finding areas with remarkable numbers to start development. Recent studies have examined the distribution of food outlets and peoples' buying habits and their food options. However, there are several studies that have presented the investigation of food outlets' distribution geographically by integrating the health issues correlations to people's habits or food distribution. This study focused on the density of food outlets, the health issues regarding the food outlets' distribution, food access areas, and its correlation in terms of income, vehicle access, and health issues. Ultimately, we also simulated an improvement to provide suggestions and strategies for enabling Guilford County to become a smart, sustainable community in terms of food access.

Planning future cities requires scientists' and planners' points of views in solving current issues and prioritizing the service sectors according to the areas' needs. As a result, concepts, such as smart cities, intelligent cities, sustainable cities, and creative cities, were invented. The definitions of these concepts vary from one author to another based on the planning priorities. Several models have been applied to investigate health-related issues. A socio-ecological model (SEM) is an approach that investigates health as influenced by environment, social, policy, and physical factors [2]. SEM investigates levels of influence at the interpersonal, institutional, community, and public policy levels [2]. This model investigated factors at each layer to understand their relationships [3]. Nevertheless, this model estimated prediction [4]. For instance, a study presented the application of the SEM model to investigate obesity-related variables such as vesical activities [3]. The layers that presented the strongest on predicting childhood obesity were neighborhood characteristics, parent demographics, and parent participation in their community [3].

According to [5], more advanced management technology can be used to manage a city's resources and provide security [5]. In city planning, food access is primarily analyzed by scientists and decision makers to show its influence on the health of people living in these areas [6]. Food security and access were measured using several methods. Several techniques and methods were applied to measure food distribution and security. Measuring the geographical location of food outlets was performed based on applying GIS methods and tools. GIS is a software manager that analyzes data based on their geographical location [7]. GIS is applied to a wide range of problems such as natural hazards and public health [8]. GIS methods were used in different food analyses such as buffering, kernel density estimation, and spatial clustering [7]. More methods were applied depending on surveys and statistical data. For instance, an example method was based on the retail food environment index (RFEI) [9]. However, some methods have limitations concerning the application and presentation of results. The RFEI method has the limitation of not covering all tracts because of the need of calculating all food outlets categories such as supermarkets [9]. A study performed in California showed that data maples covered only 3719 out of 7049 based on the RFEI method [9].

Techniques, such as machine learning, are now used for research related to food security, as they are highly data-driven models. Machine learning (ML) is a programming technique that is used to solve nonlinear problems efficiently. It has models and algorithms, where the algorithm executes on the data to create the model [10]. It has serval different models to investigate relationships and compare results. The ML techniques were used to solve major problems such as classification, regression, reinforcement, and clustering [11]. The regression analysis was applied to detect continuous metric output [12]. Regression problems were investigated by several models, for instance, linear and nonlinear regression. These models also worked in hyper feature space for illustrating the relationship and were applied to different scientific fields [13]. A further example is the K-nearest neighbors regression model, which presents appealing results for small data [14]. 
Random forest regression models, as part of tree multioutput regression, were used to predict the variables [12]. More than one regression analysis can be used in comparison to find the best-suited model for higher performance. A study investigated food security using machine learning models (extreme gradient boosting, random forest, and CatBoost) to predict monthly variations [15]. This study investigated data involving food choices, income, geographical location, and climate [15]. It showed Xgboost was the best model and better results were presented when fewer changes in time and place accrued [15]. A further study in food security discussed the application of machine learning techniques to predict the modified retail food environment index (mRFEI) and found that a food desert differs from a food swamp thereby necessitating the application of different policies [16].

Furthermore, sustainable communities give priority to people's health [5]. However, currently, it is recommended to use smart and sustainable terms as one concept, which converges the application of data-driven technologies of smart cities with the key goal of creating sustainable communities to provide an equal right to the benefits and an equal access to healthy food [17].

Studying the distribution of food outlets involves studying the distribution of groceries, restaurants, and residents' density. Food access can be analyzed by studying the two key elements known as a food desert and a food swamp. Food swamps are areas with more unhealthy food options than healthy food options [18]. On the other hand, food deserts represent areas with low access to healthy food, and the expected distance was 500 meters, 0.3 miles, or 5-7 minutes of walking [19]. The characteristics of food deserts include availability of inexpensive food, poor nutrition, and limited healthy items in small stores [18]. Food insecurity is not only the critical area to be investigated. The availability of food sources is also very important. Food oases represent areas where people have an abundance of healthy food options rather than unhealthy food options [20]. In another study, the difference between food item prices was investigated with respect to food access areas, food deserts, food swamps, and food oases, and it was determined that there were no remarkable differences in the process [20].

Several studies investigated the influence between food distribution and other variables such as location, transportation, time, and behavior. A study of 36 counties of a suburban area showed that these areas suffered because residents needed to travel up to 30 miles for healthy food access [21]. Another study analyzed food access in the suburban areas and rural areas of Louisiana and determined that suburban areas near urbanization had greater access to healthy food [22]. Time could be analyzed by two dimensions including the time of events (such as weather events) and the time of source existence (such as food trucks and farmers' markets) [6]. For example, the accessibility of food by walking was found to be different in summer than in winter, as the time of the year and day were different. As a result, in the case of a health disaster, socially isolated communities with food scarcity were most severely affected [23]. A study applied GIS and analyzed people's access to transportation where the results indicated the importance of transportation access to improve people's food choices [24]. Another study analyzed people's behavior using data from an application designed for people to donate food [25]. The results showed a correlation between a higher number of donations points and more bus stops as a means of access to transportation [25].

Analyzing food access is a complex process that includes observing the current distribution of food outlets and analyzing the residents using different methods, factors, and scenarios. These factors were transportation access to supermarkets, the ethnic group of population distribution in food deserts, economic status, and chain and non-chain stores [26]. A study by Eckert and Shetty (2011) used block methods in geographic information systems (GIS), which applied network analysis to determine the distance between each resident and the grocery store (considering the residents' ethnic group and income) [27]. The result showed that there was no connection between income and ethnic group in relation to food access [27]. Regarding chain and non-chain stores, a report by the Economic Research Service (ERS) explained that smaller stores sold smaller packages at a higher 
cost compared to supermarkets and non-chain stores [26]. Moreover, they were typically situated in poorer areas [26]. Another study showed that more options for greater food items were available with lower prices in supermarkets compared to small stores [28].

One study on food access and its consequences examined the relationship between fast-food restaurants and obesity in the surrounding areas [29]. The study considered two miles as the accessibility distance to analyze the health records but found no connection between obesity and fast-food accessibility [29]. Another study in Philadelphia, which was considered the second lowest in food access among major cities nationally, concluded that many low-income and food access neighborhoods had a high number of health challenges such as diabetes, heart diseases, and cancer [26]. An additional study also found a connection between food deserts, low income, lack of transportation, and diabetes [30].

There have been several studies on the consequences of inadequate food distribution, and they included the number of diseases spreading. Healthy food access was a key factor in the obesity epidemic, and the high consumption of unhealthy food was a critical factor in diabetes, hypertension, cancer, high mortality rates, and life loss [18]. There were some studies on the health risks and mortality rates regarding food access, and some of these suggested looking into the factors of these rates after mapping them. A study by Cossman and others (2003) mapped the mortality rates in every county in the United States for 30 years and determined the highest and lowest mortality rates [31]. The study suggested looking into the continuous high mortality in a county and analyzing it to determine the involved factors [31]. Another study looked into mapping health issues, such as tuberculosis, and the correlation with human development such as food access, income, education, and health [32]. The study concluded that there was a connection between human development and tuberculosis [32], where neighborhoods with less than the average income and education had higher tuberculosis rates [32]. A further study illustrated the investigation of type 2 diabetes per county level by machine learning [33]. Its results illustrated no correlation between the health issue and the variables of physical activities, access to exercise, and food environment [33].

Several limitations on food access were presented in recent studies. A large percentage of studies focused on only one to two outlets or categories, and only a few investigated the effect of all types of food outlets [34]. Another method's limitation involved hypothesizing that people's health was only influenced by the stores located closed to their residential location [34]. A further limitation involved using separate methods concerning food, where nutrition studies were separated from food environment research (combining them with the support of more methods and techniques would present a comprehensive overview of food access and health consequences) [34].

The reviewed literature illustrated that several studies focused on a few parts or variables of the overall problem regarding food access, health issues, and regional distribution. We studied all food access areas together with their influence on three health issues as a holistic case and to help local authorities in decision making for future planning. According to the literature review, food scarcity was studied in the form of a food desert and food swamp but lacked their influence on health conditions and the comparison to food abundance. The research questions in this study were:

Using GIS spatial mapping, can we find possible correlations between food access distribution and health risk issues?

Do health issues depend solely on univariate food access distribution or multivariate analysis of transportation access, income, population, and food access?

Can the linear or nonlinear ML regression models be developed for dependent variable health risks with better determinant coefficient?

This study addressed the gap by finding the correlations of food desert factors, food swamps, and food oases impacting on health issues and mortality using geospatial information analysis, surveys, and machine learning techniques. Our contributions in this study included reporting the results of:

Investigating the geospatial correlation between food distribution and health issues; 
Comparing the number of health issues between food access areas;

Estimating the statistical correlation between health issues and several variables;

Comparing the results of the regression analysis models regarding health issues related to several variables.

\section{Materials and Methods}

We examined Guilford County in North Carolina as our study area (Figure 1) including tabular attribute data. Data were obtained from the Health Department in Greensboro based on a crude survey, USDA Environmental Atlas, and the American Community Survey. Health records were collected by the North Carolina Department of Public Health. These data were geolocated by tracts. The data included income, food outlets, health records, low transportation aces, and mortality rates. Health records included (i) high cholesterol, where cholesterol was higher than $240 \mathrm{mg} / \mathrm{dL}$ and higher than $18 \%$ lipoprotein density; (ii) high blood pressure, where the systolic was $140 \mathrm{~mm}$ and diastolic was $90 \mathrm{~mm}$ or higher; (iii) obesity as defined by the World Health Organization, when an individual's body mass was greater than 30 [35-37]. At the time of this study, Guilford County aimed to become a smart, sustainable community. With a population of 533,670 within 645.70 square miles, it was the third most populated county in North Carolina and was also among the top five most densely populated counties in the state of North Carolina [20]. It was also the largest county in terms of acreage [38,39]. Guilford County had 118 census tracts, and it covered the cities of Greensboro and Highpoint and eight towns consisting of Gibsonville, Jamestown, Oak Ridge, Pleasant Garden, Sedalia, Stokesdale, Summerfield, and Whitsett. The county was identified primarily as a food desert in 2014 [1]. The median household income in this county was $\$ 51,072$ [39]. Methods (see Figure 2) included applying GIS and regression analysis. The GIS method was selected to investigate the geographical correlation, and the regression analysis was conducted to combine it with statistical association. Regression analysis is a machine learning technique that can be applied to forecast prediction or investigate relationships [40]. Regression models were applied (as multioutput regression and multiple linear regression) to present relationship and compare their results. The mathematical foundation lies in deriving the nonlinear relationship of the dependent variable against the multivariate independent variables. We based our nonlinear multivariate regression model with a polynomial of the order 3 and 3 independent variables giving up to $2^{\mathrm{n}}-1$ coefficients. We compared this model against the other ML models and found that the random forest regression model performed better next to the nonlinear multivariate regression model. The hyper dimensional feature space transformation in the random forest technique yielded a better performance. 


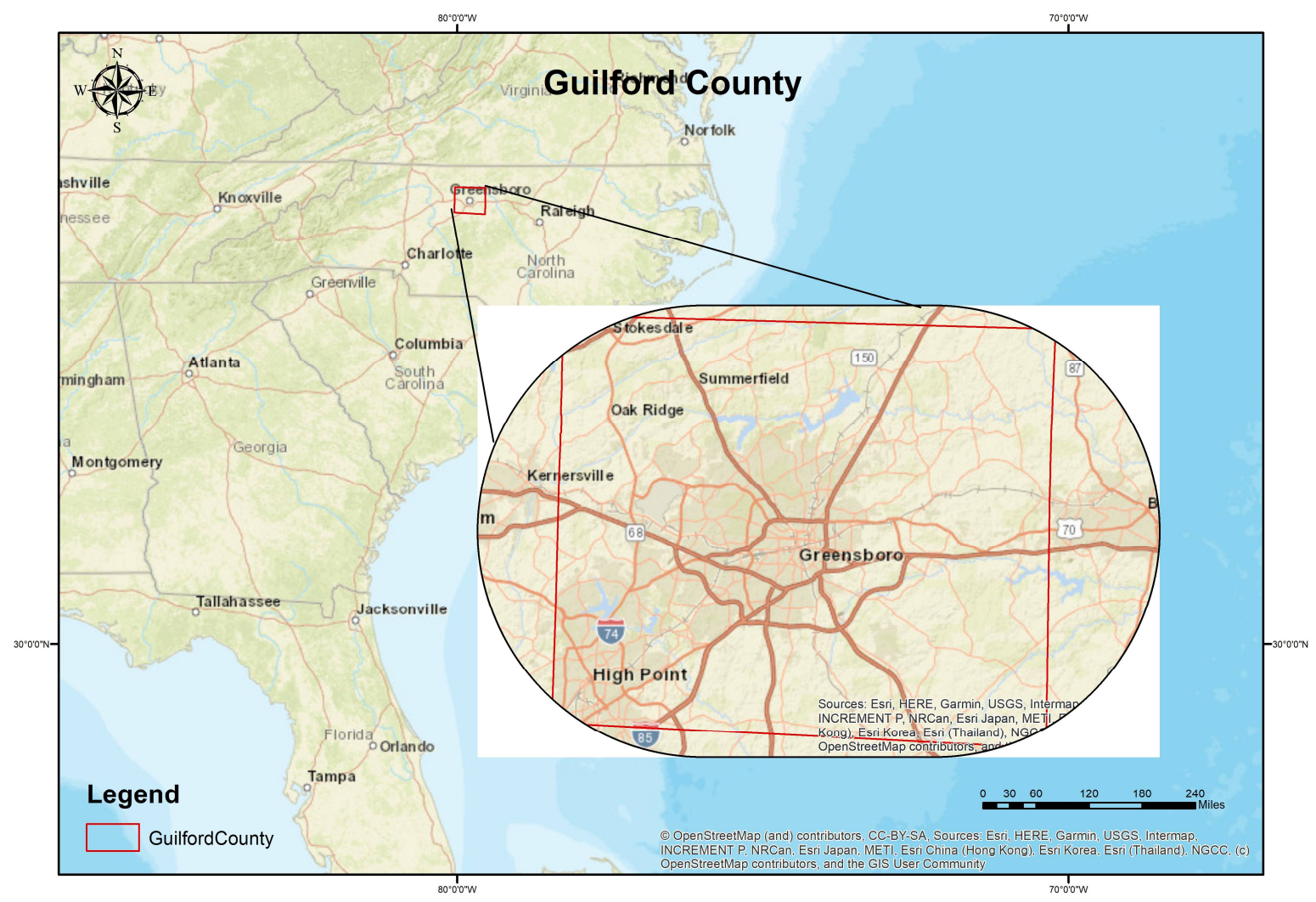

Figure 1. Study Area: Guilford County, North Carolina.

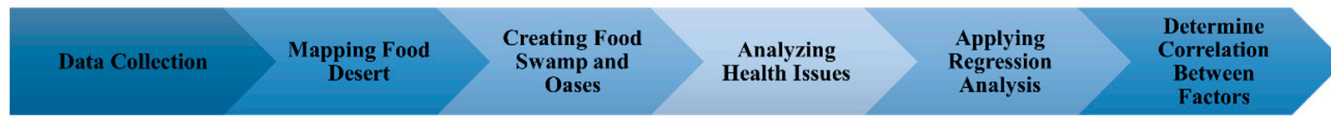

Figure 2. Methods.

\subsection{GIS Method}

First, we developed the geospatial maps of health (Figure 3) and mortality outcomes for Guilford County. Figure 4 llustrates the geospatial map of heart disease-related mortality rates in Guilford County by percent in each census tract. The descriptive statistics of these health issues are presented in Table 1.

The mortality rate due to the fact of heart diseases ranged between $0.002 \%$ and $0.008 \%$ per census tract. Figure 3 shows that there was a high density of obesity and high blood pressure in central Greensboro, Downtown, and Highpoint (outlined in the bounding box). It also coincided with the high density of high cholesterol issues. Notice that the density markers of high cholesterol had higher percentages than hypertension markers. These density maps were developed using the point density tool in ArcGIS software and were overlayed against the obesity density map. Interestingly, the west part of Guilford County showed low obesity numbers. However, high cholesterol and high blood pressure numbers were shown in few census tracts. The distribution of high blood pressure and high cholesterol showed a higher density around Greensboro and Highpoint, too. Figure 5 shows the mean household income distribution of Guilford County with obesity distribution. A low income was from USD 0 to 30,604, a middle income was between USD 30,604 and 91,812, and a high income was more than USD 91,819 per year [41]. The overall mortality rate map shows a similar pattern in the downtown Greensboro and High Point cities. 


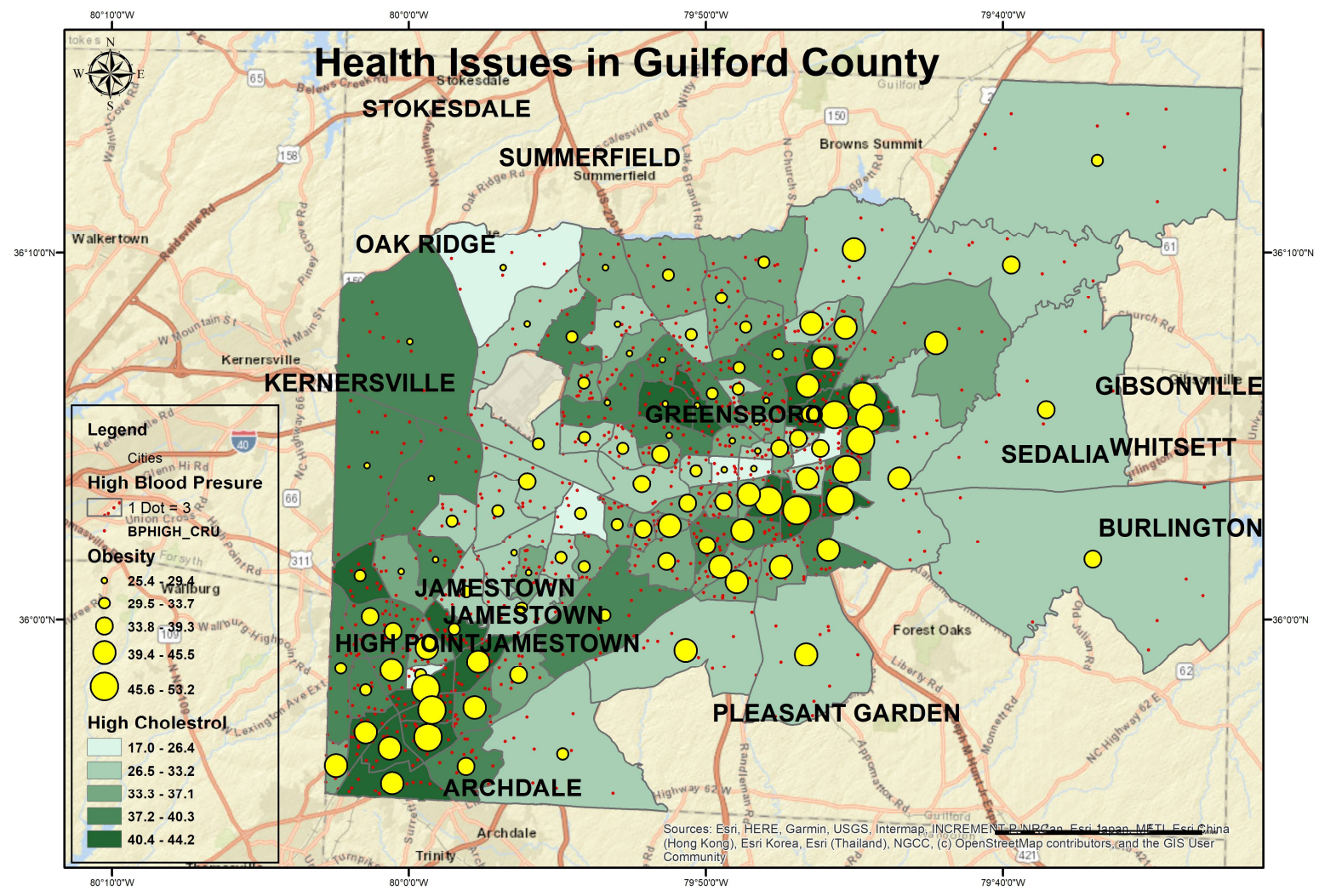

Figure 3. The distribution of health issues (i.e., high cholesterol, hypertension, and obesity) in Guilford County.

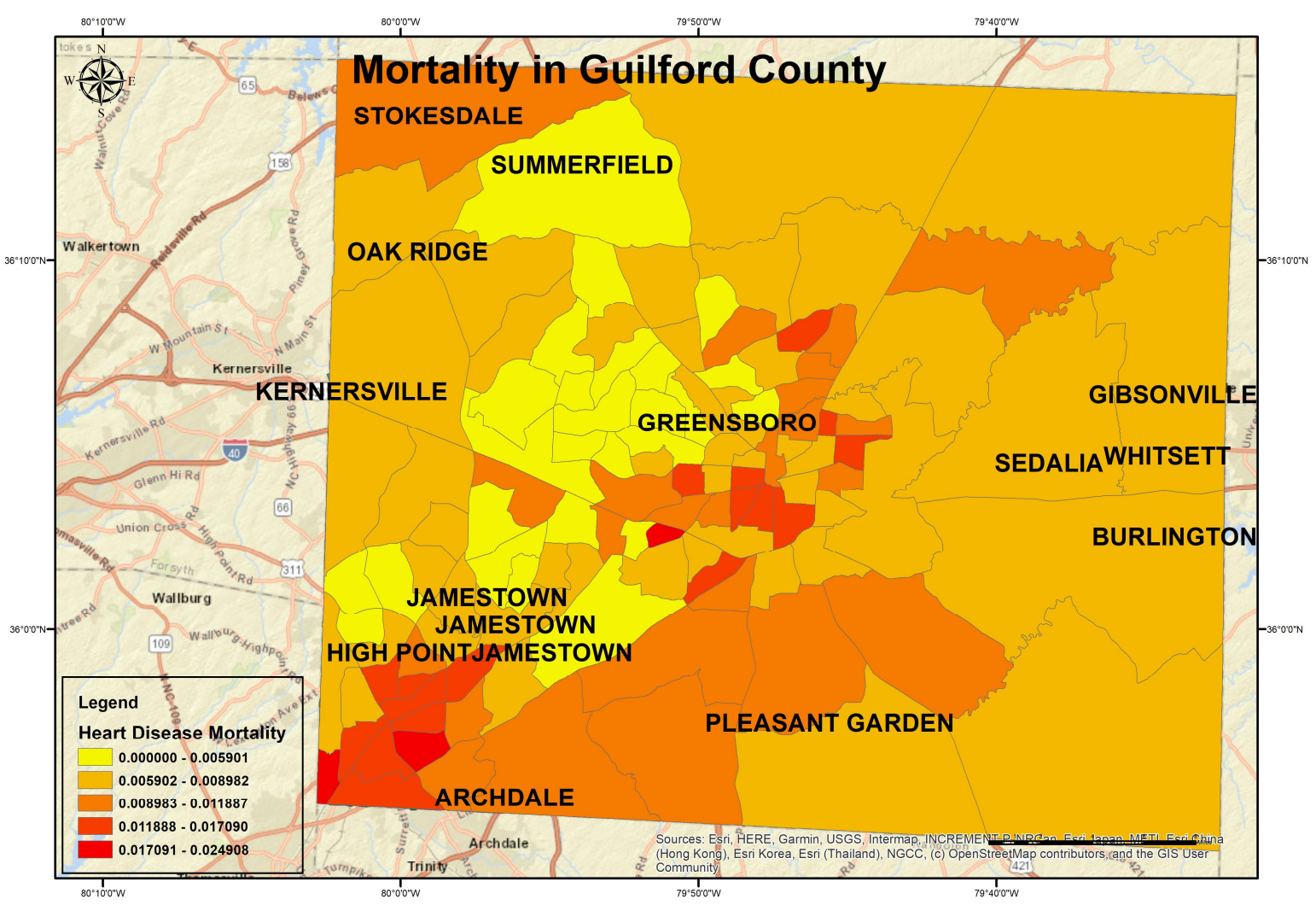

Figure 4. Heart disease mortality rates in Guilford County. 
Table 1. Descriptive statistics.

\begin{tabular}{cccccc}
\hline Statistics & $\begin{array}{c}\text { Median } \\
\text { Income } \\
\text { (USD) }\end{array}$ & Population & $\begin{array}{c}\text { High Blood } \\
\text { Pressure }\end{array}$ & $\begin{array}{c}\text { High } \\
\text { Cholesterol }\end{array}$ & Obesity \\
\hline Mean & $51,440.06$ & 3979.78 & $34.10 \%$ & $35.70 \%$ & $35.87 \%$ \\
SD & $25,725.97$ & 1498.57 & $7.59 \%$ & $5.01 \%$ & $7.13 \%$ \\
Minimum & $14,695.00$ & 1300.00 & $13.30 \%$ & $17.00 \%$ & $25.40 \%$ \\
$25 \%$ Quartile & $33,889.00$ & 2862.00 & $28.80 \%$ & $32.80 \%$ & $29.90 \%$ \\
$50 \%$ Quartile & $47,500.00$ & 3903.00 & $33.10 \%$ & $36.20 \%$ & $34.20 \%$ \\
$75 \%$ Quartile & $60,653.00$ & 5063.00 & $38.00 \%$ & $39.60 \%$ & $53.20 \%$ \\
Maximum & $170,625.00$ & 7791.00 & $55.00 \%$ & $44.20 \%$ & $53.20 \%$ \\
\hline
\end{tabular}

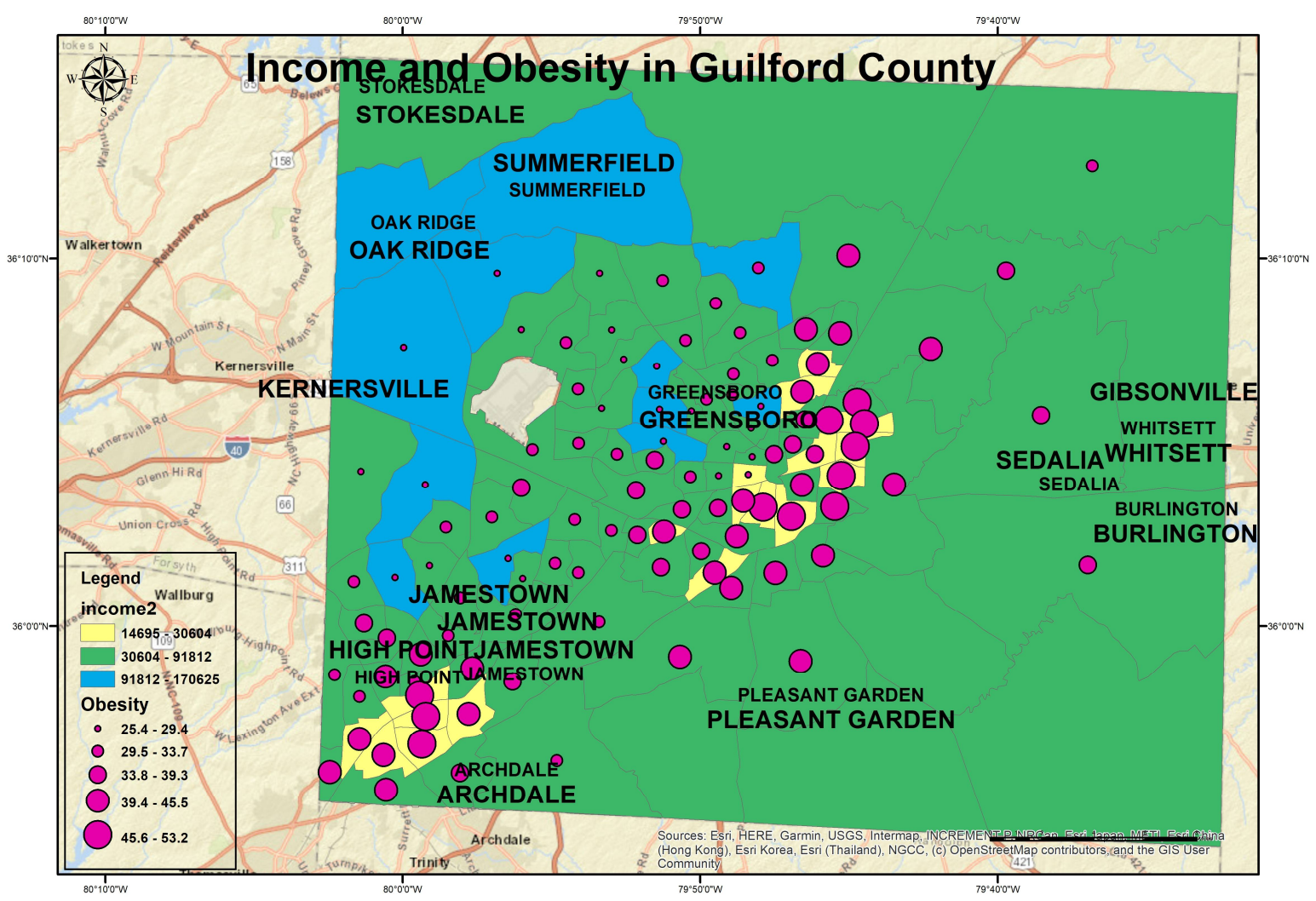

Figure 5. Income and obesity in Guilford County.

Later, we calculated the total number of healthy and unhealthy food outlets per census tract using the tabulate intersect method, which gave the result in a tabular format. Afterward, the resultant table was joined to the study area using the "Mathematical Join" option. The census tract shapefile was used to find the areas with higher unhealthy food from the intersection of healthy and unhealthy outlet maps in Figures 6 and 7. We then performed spatial analysis using the clip tool in the ArcGIS software to find the number of health issues and the mortality rates in all three food access areas (see Table 2).

Table 2. The statistics (mean and standard deviation) of health issues, density, income, and mortality rates in each food access area.

\begin{tabular}{|c|c|c|c|c|c|c|}
\hline & Income (USD) & $\begin{array}{l}\text { Population; } \\
\text { Acreage }\end{array}$ & $\begin{array}{l}\text { High Cholesterol } \\
\text { (Mean, SD) }\end{array}$ & Obesity (Mean, SD) & $\begin{array}{l}\text { Hypertension } \\
\text { (Mean, SD) }\end{array}$ & Mortality (SD) \\
\hline Food Deserts & $41,369.35$ & $105,695,1418$ acres & $36.5 \%, 5.34 \%$ & $42 \%, 6.52 \%$ & $38.8 \%, 8.38 \%$ & $0.01 \%$ \\
\hline Food Swamps & $51,783.43$ & $189,166,6485$ acres & $35 \%, 4.39 \%$ & $34 \%, 6.63 \%$ & $32 \%, 6.75 \%$ & $0.0085 \%$ \\
\hline Food Jungle & $60,595.80$ & $13,847,27,584$ acres & $37 \%, 5.58 \%$ & $35 \%, 7.84 \%$ & $36.25 \%, 7.00 \%$ & $0.0079 \%$ \\
\hline
\end{tabular}




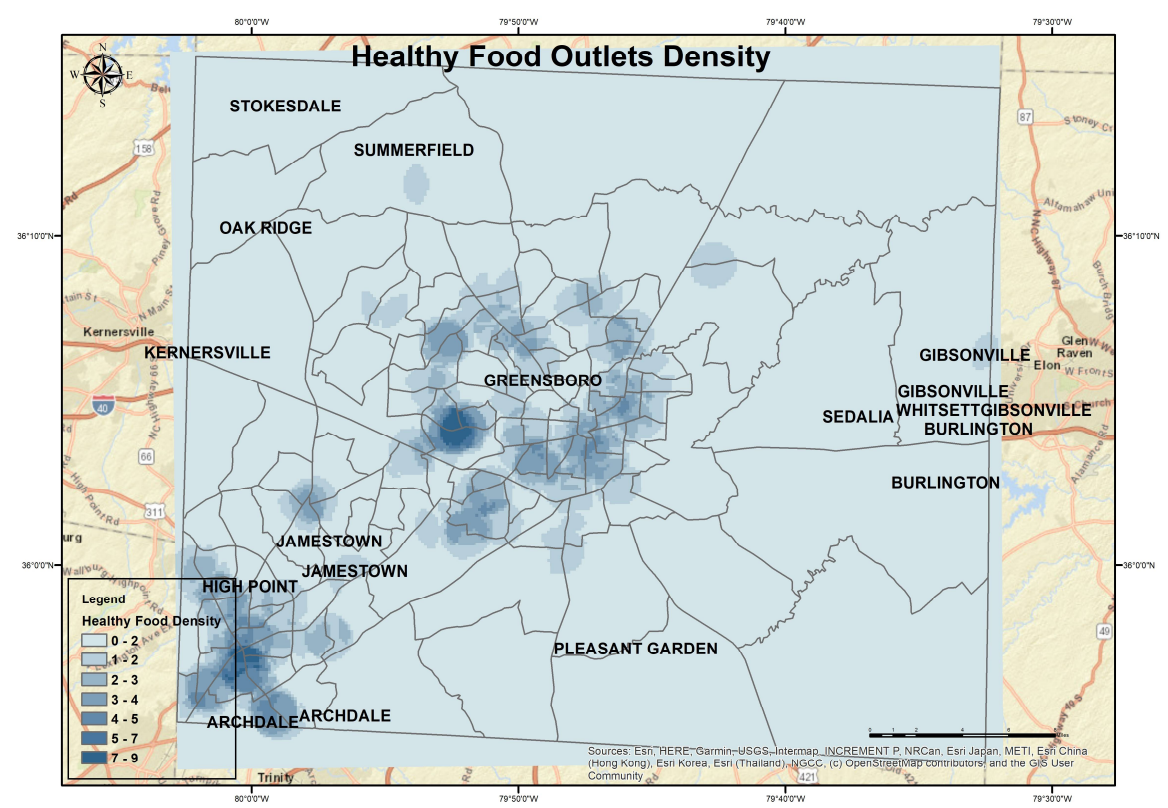

Figure 6. Geospatial map showing the density of healthy food options.

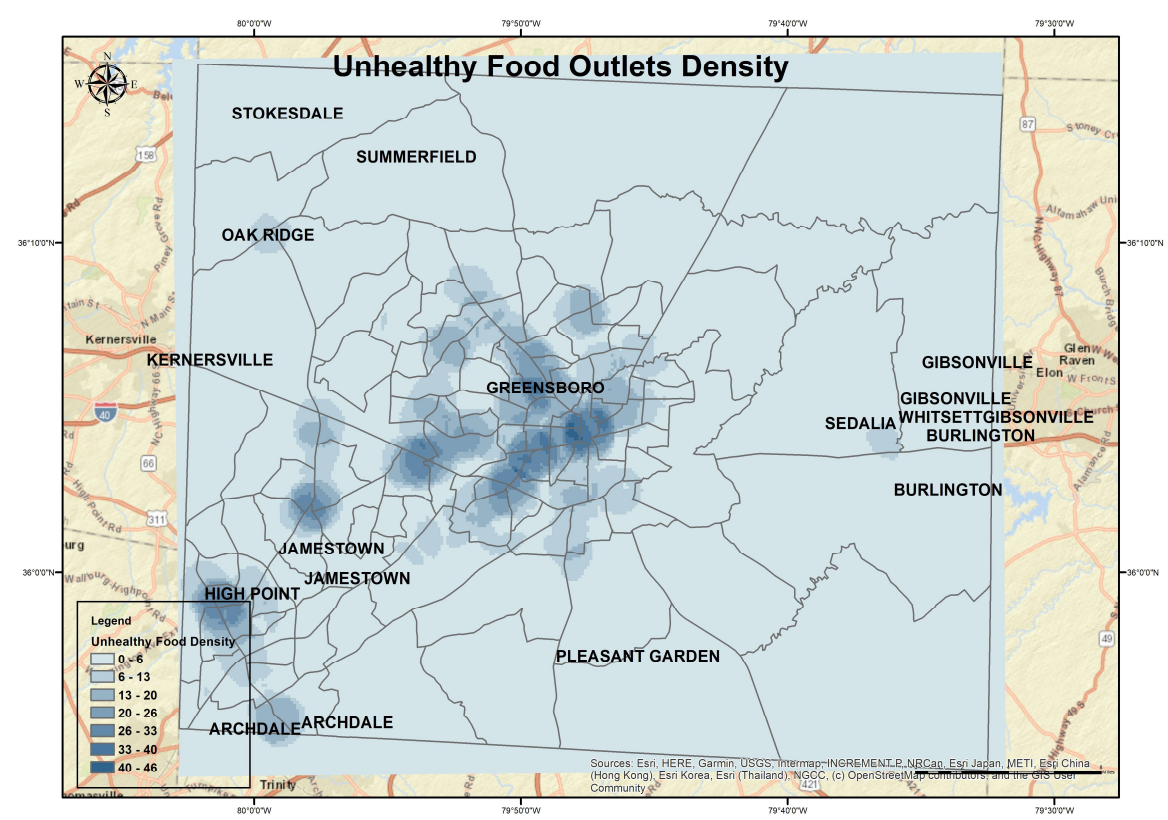

Figure 7. Geospatial map showing the density of unhealthy food options.

Next, we developed geospatial maps of the three food access areas. Based on healthy food access, Guilford County was divided into three food geographies: food deserts, food swamps, and food oases (Figure 8). Food deserts were measured based on the USDA Economic Research Service definition as the census that had a poverty rate defined as more than $20-30 \%$ of its people living more than 1 mile away from a full-service supermarket [42] In addition, we included where the minority rate was higher, i.e., more than $30 \%$ of the total population $[43,44]$. A food desert is presented in the equation below:

Food desert $=$ low access to supermarkets (the tracts with more than $30 \%$ of its people in more than one mile from supermarket) + low car access (households with no personal transportation) + high poverty rate + low income ( $<$ USD 30,000 p.a.).

The food desert method started by buffering 1 mile around supermarkets and applying the symmetric differences tool to find the tracts with $30 \%$ of the population living one mile away from supermarkets. After that, we applied the intersect tool to the previous layer with the layers of low income, low car access, and high poverty. 


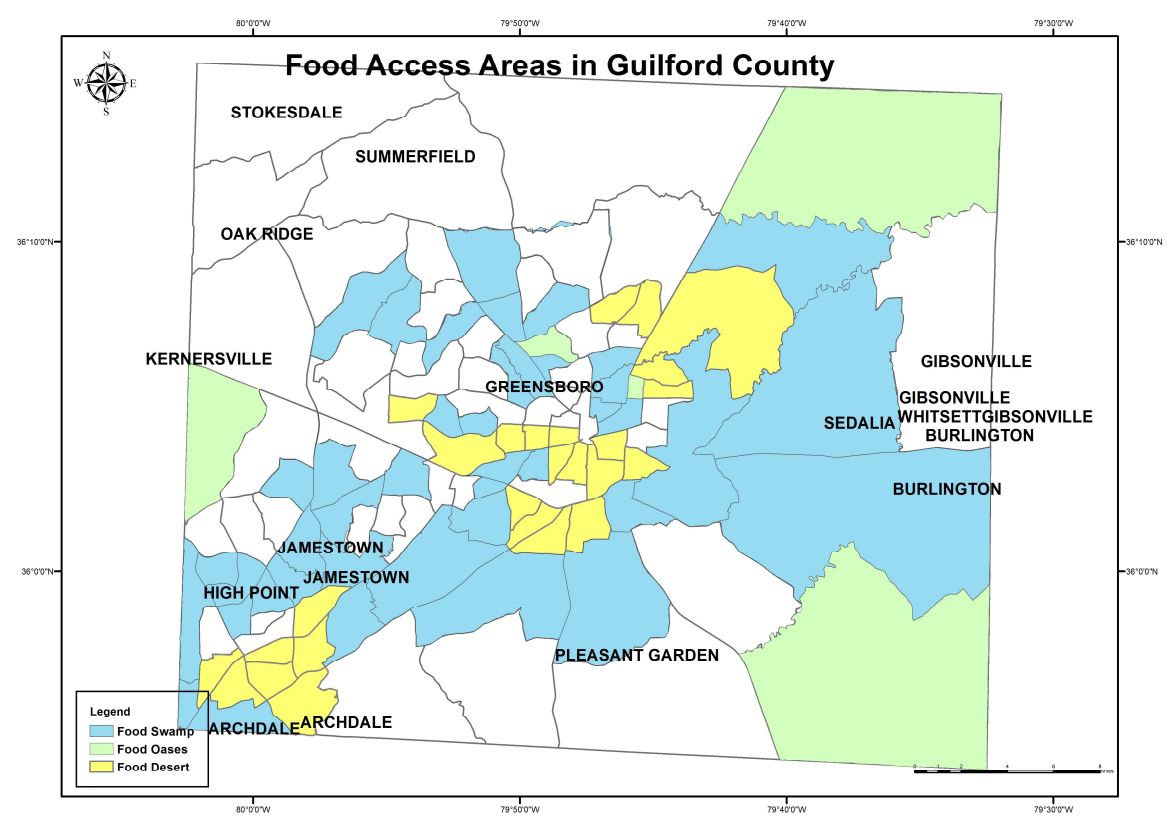

Figure 8. Geospatial map of food access in Guilford County.

The method started by buffering 1 mile around supermarkets and applying the symmetric differences tool to find the $30 \%$ of the population that was more than one mile to supermarkets. Afterward, we applied the intersect tool to the previous layer with the layers of income and poverty. Then food deserts showed areas where residents had scarce access to nutritious food. Geospatial mapping of food deserts in Guilford County was developed by identifying areas with the following overlapping characteristics: (i) healthy and unhealthy food density (Figures 6 and 7); (ii) high population density; (iii) high poverty and low income (Figure 5); (iv) low access to transportation. A food desert is a census tract that has less than a $20 \%$ poverty rate and at least $30 \%$ of its population lives more than one mile from supermarkets.

Afterward, we identified food swamps and food oases. A food swamp had more unhealthy food outlets than healthy outlets, but a food oasis had more healthy than unhealthy food options. Food outlets were categorized as healthy based on fresh food availability such as supermarkets and farmers' markets. Unhealthy food outlets were packed, and fast food was sold in various places such as restaurants and convenience stores. To develop the food oases and swamp geo-maps, we categorized healthy and unhealthy food outlets (Figures 6 and 7). The healthy outlets were where fresh vegetables, fruit, and meat were available. This category contained supermarkets, grocery stores, meat markets, farmers' markets, community gardens, farm road stands, and food parties. Although the second category represented relatively unhealthy food, it comprised convenience stores, dollar stores, and restaurants. We computed the density maps for healthy and unhealthy food outlet stores (Figures 6 and 7) using the region growing density tool. These density maps present the volume of stores for each category. For healthy food outlets, the highest number of stores ranged between 5 and 6 (dark spots in Figure 6), and the lowest was 0-2. For unhealthy food outlets, the highest number of outlets ranged between 40 and 46 stores (dark sports in Figure 7), and the lowest was 0-6.

We computed the descriptive statistics (i.e., mean values and standard deviation) of each health issue in these food access areas for correlation analysis. We used the clip tool additionally to merge the income layer by each food access area to compute the mean household income for Table 2. After developing the overall map showing the three food access areas' geographies (Figure 8), we compared the health records in each area to determine if there was an effect of healthy food access on health and mortality outcomes. The spatial analysis method showed positive correlations among food outlets and health issues, mortality rates, and income. The results are corroborated in Table 2. 
In Table 2, the percentage of the population in food access areas may not provide a clear illustration of the number of people impacted by health issues. For instance, the quantity of $36.5 \%$ of the population in food deserts having high blood pressure was 38,578.674, which was higher than $37 \%$ of the population in the food jungle (consisting of 5123.39).

\subsection{Multioutput Regression and Multiple Linear Regression}

We used machine learning techniques to examine the quantitative analytics of population and median income on health issues by specifically applying multioutput regression and multiple linear regressions. Multioutput regressions are regression problems that involve predicting two or more numerical values given several independent variables. The multioutput algorithm is more efficient than the single-output algorithm, because the relations among outputs can be estimated simultaneously by the proposed prediction model. Moreover, application of more than one regression was necessary to compare their results. In this work, we predicted high blood pressure rates, high cholesterol rates, and obesity rates based on the inputs (independent variables) of population, income, and low car access.

The data set was divided into $80 \%$ training and 20\% testing for multioutput model development. The training set contained eighty-seven (87) observations and twenty-two (22) observations in the testing set, and two different metrics: root mean square (RMS) and R-Squared ( $\left.R^{\wedge} 2\right)$ which were used to evaluate the models developed. The implementation of multioutput and multiple linear regression models was conducted with the Sklearn package in Python and MATLAB 2020a, respectively. The default parameters for the multioutput regression models are shown in Table 3.

Table 3. Regression models' parameters.

\begin{tabular}{|c|c|}
\hline Model & Parameters \\
\hline Linear Regression Model & copy_X=True, fit_intercept=True, $n \_j o b s=$ None, normalize=False. \\
\hline Decision Tress Regression Model & $\begin{array}{l}\text { 'ccp_alpha': } 0.0 \text {, 'criterion': 'mse', 'max_depth': None,'max_features': None, } \\
\text { 'max_leaf_nodes': None,'min_impurity_decrease': 0.0, 'min_impurity_split': None, } \\
\text { 'min_samples_leaf': 1,'min_samples_split': } 2, \text { 'min_weight_fraction_leaf': } 0.0, \text { 'presort': } \\
\text { 'deprecated', 'random_state': None, 'splitter': 'best' }\end{array}$ \\
\hline Random Forest Regression Model & 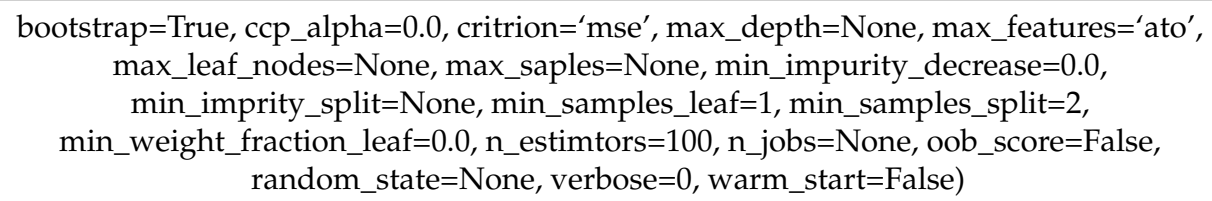 \\
\hline K-Nearest Neighbor Regression Model & $\begin{aligned} \text { lgorithm': 'auto', 'leaf_size': 30,'metric': 'minkowski', 'metric_params': None, 'n_jobs': } \\
\text { None, 'n_neighbors': } 5, \text { 'p': 2, 'weights': 'uniform' }\end{aligned}$ \\
\hline
\end{tabular}

The below equation, based on multivariate linear regression, was applied to predict and investigate the relationship between variables, where 49.855 and 0.00029 were the coefficient for the median income variable, 13.233 was the coefficient for car access, and 0.00025 was the coefficient for the interaction between median income and low car access.

$\mathrm{y}=49.855-0.00029 *$ MedIncome +13.236 * Low Car Access - $0.00025 *$ MedIncome * Low Car Access.

\section{Results and Discussion}

\subsection{Geospaital Correlation}

Figures 5 and 6 show geospatial maps of the density of healthy and unhealthy food outlets in Guilford County. In Figure 6, the highest density cluster represents nine healthy and fresh food stores. They were located in the southwest of the county central and the south of the county. In Figure 7, the unhealthy density shows that 42 was the highest number of unhealthy food outlets in a square mile. These clusters were in central Greensboro 
downtown and Highpoint downtown. Overall, some of the high-density clusters of healthy and unhealthy food were co-located, but the highest cluster for each one was in different areas and varied by four times. With respect to the high-density clusters of unhealthy food that were merged with the defined food desert areas, it appeared as though they had access to more unhealthy food. However, because of other factors (income, population density, and low access to transportation), it represented a food desert where people were unable to access them within a one-mile walking distance. When comparing the mean values of the two food deserts and food oases, it was evident the lower-income household areas had higher obesity, higher hypertension, and higher mortality rates, whereas the high cholesterol mean values were lower in food desert areas. The food swamp areas had low mean values in all health issues in comparison to food jungle areas.

The food access map (Figure 8) and Table 2 both show fewer health issues and mortality rates in food swamps and food oases compared to food deserts due to the better access to healthy food outlets in these two areas. In addition, there was a strong, positive correlation between income and food access, because it facilitates people with the ability to access food stores by car or via another affordable transportation type. Higher access to personal and public transportation showed a negative correlation between health issues and mortality rates. For example, higher-income areas in food oases had fewer health issues and lower mortality rates. The statistics also clearly showed that the food swamps with more unhealthy options were still better than food desert areas with no food access in a mile radius, causing a higher rate of health issues and mortality. These results showed the high numbers of health issues and mortality rates in food desert areas (where more health services, health awareness, and disaster risk preparedness were required for future planning by the county).

The food access map covered only part of the county based on the category qualification applied. However, some areas on the outskirts of the county were not categorized by any of the food access categories (Figure 8), and this could represent a balanced or neutral category of food access area with medium income, medium transportation access, medium food access, and medium population density. Moreover, these areas could have more variance in health statistics and less population density.

\subsection{Regression Analysis Results}

We conducted machine learning based regression analysis to validate the quantification of dependency relations the food deserts against health factors similar to spatial maps [26-28]. We used both linear and nonlinear models such as linear, K-nearest neighbors, decision trees, and random forest. The linear regression independent produced results for a single output at a time, while the other models produced all output at the same time. The aims of using these models were to explore all models, compare their results, and find the more suitable model for food distribution related problems. The Pearson correlation coefficients $\left(R^{2}\right)$ matrix indicates degrees of linear association among a set of variables as shown in the correlation matrix heatmap in Figure 9. $R^{2}$ values close to 1 indicate that there is a positive linear relationship between the data columns. Values close to -1 indicate that one column of data has a negative linear relationship to another column of data. The $R^{2}$ values close to or equal to 0 suggest there is no linear relationship between the data columns. The diagonal of the correlation matrix was 1 throughout because there was a positive relationship between all the variables with themselves. It can be observed from the correlation heatmap that there existed a strong correlation between high blood pressure and high cholesterol $\left(R^{2}=0.82\right)$ in Figure 9. In addition, the same could be said for obesity and high blood pressure $\left(R^{2}=0.77\right)$. However, there was a strong, negative correlation between income and obesity $\left(R^{2}=0.7\right)$ in Figure 10. Moreover, there was no relationship between obesity and high cholesterol, as it did not show any negative or positive $\left(R^{2}=0.34\right)$ and substantiated similar to the GIS map in Figure 4. 


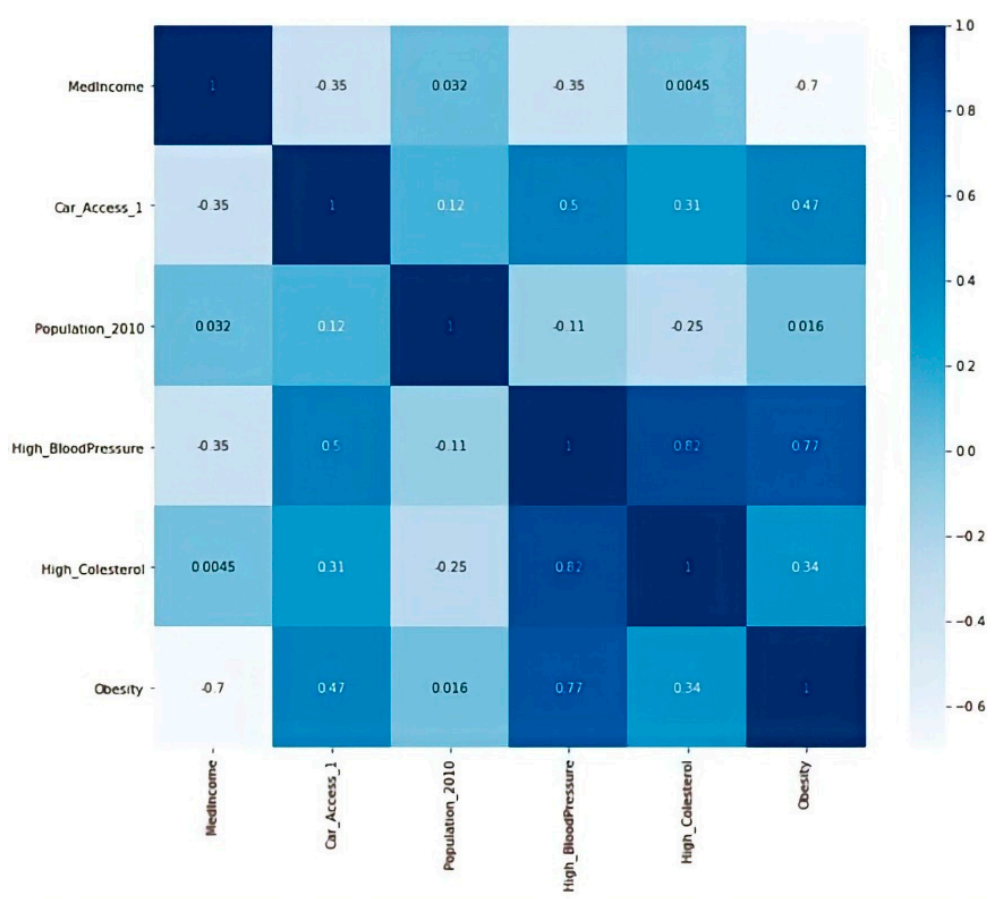

Figure 9. Correlation matrix with heatmap.
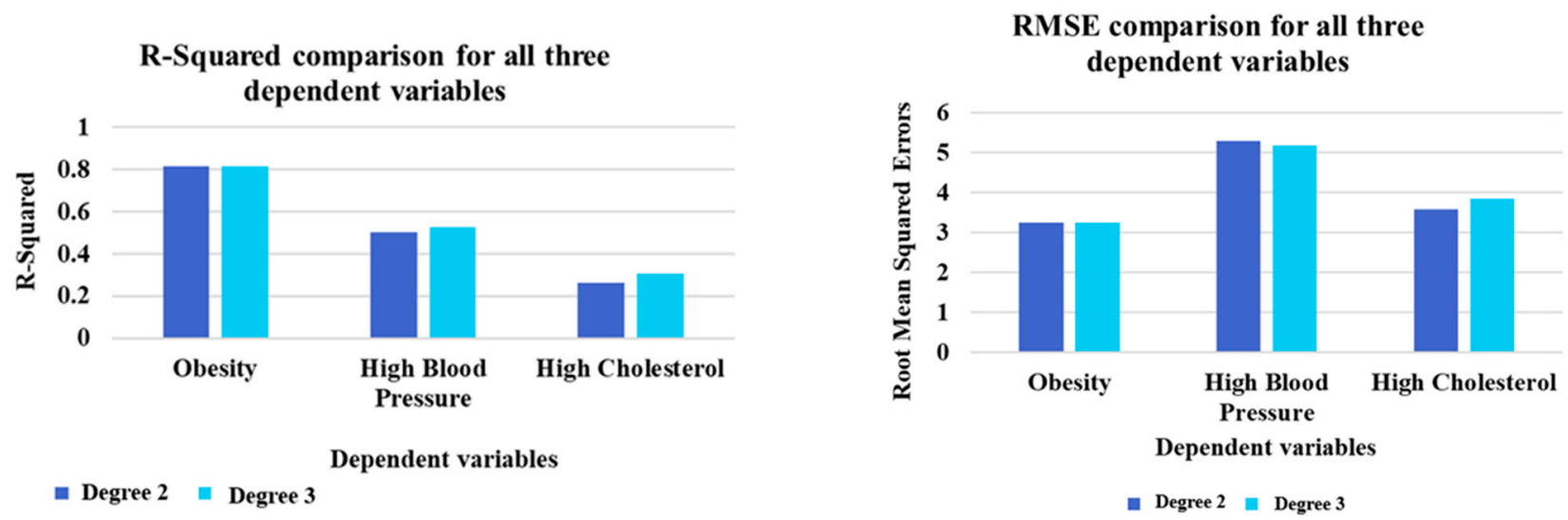

Figure 10. R-Squared and RMSE comparison of multivariate polynomial regression of second and third degrees.

\subsubsection{Multioutput Regression Models}

Multioutput regressions are regression problems that involve predicting two or more numerical values given several independent variables. The multioutput algorithm is more efficient than the single-output algorithm because multiple outputs can be estimated simultaneously by the proposed prediction model.

Based on the R-Squared values in Tables 4 and 5 below, none of the multioutput regression models can be recommended. Nevertheless, the R-Squared values of all four models with obesity as a dependent variable consistently achieved a higher score, with the highest being approximately $79 \%$. The independent variables, namely, median income, low car access, and population, had a significant influence on obesity rate and a negative correlation with high cholesterol. 
Table 4. R-Squared values of the k-nearest neighbors, random forest, and decision tree for multioutput regression.

\begin{tabular}{cccc}
\hline \multicolumn{1}{c}{ Models } & R-Squared & Obesity \\
\hline Linear regression for multioutput Regression & 0.375 & High Cholesterol & 0.600 \\
K-nearest neighbors for multioutput regression & 0.349 & 0.236 & 0.771 \\
Random forest for multioutput regression & 0.350 & 0.054 & 0.797 \\
Decision tree for multioutput regression & -0.261 & -0.806 & 0.586 \\
\hline
\end{tabular}

Table 5. Root mean square error (RMSE) values of k-nearest neighbors, random forest, and decision tree for multioutput regression.

\begin{tabular}{cccc}
\hline & & Root Mean Square Error \\
\hline Models & High Blood Pressure & High Cholesterol & Obesity \\
\hline Linear regression for multioutput regression & 5.348 & 3.921 & 4.417 \\
K-nearest neighbors for multioutput regression & 5.50 & 4.385 & 3.347 \\
Random forest for multioutput regression & 5.457 & 4.363 & 3.149 \\
Decision tree for multioutput regression & 6.733 & 5.682 & 3.792 \\
\hline
\end{tabular}

\subsubsection{Multiple Linear Regression Models}

Implementation of the multiple linear regression models on the data set was evaluated considering the three dependent variables separately. The value of the coefficient of determination (r-squared) when high blood pressure and high cholesterol were used separately as dependent variables remained significantly low with or without interaction terms. The R-Squared value obtained from these models was below $40 \%$. However, promising results were achieved when "obesity" was used in the multiple linear regression model as a dependent variable. Table 6 presents the independent variables and dependent variables for the multiple regression model. The predictors or features were transformed to give interaction terms to improve the model (as presented in Table 7). This means approximately $81 \%$ of the variability in the obesity rate (dependent variable) was explained by the independent variables (high blood pressure rate, high cholesterol rate, and obesity) in the multiple linear regression model. There existed a significant interaction between the variables median income and low car and transportation access.

Table 6. Variables for multiple linear regression model development.

\begin{tabular}{cc}
\hline Inputs & Output \\
\hline Population & Obesity Rate (Figure 2) \\
Median Income (Figure 6) & \\
Low Car Access & \\
\hline
\end{tabular}

Table 7. Results for the multiple linear regression using obesity as a regressor.

\begin{tabular}{cccccc}
\hline Interaction Terms & Normalization & $\begin{array}{c}\text { Outlier } \\
\text { Removal }\end{array}$ & $\begin{array}{c}\text { Root Mean Square } \\
\text { Error }\end{array}$ & $\boldsymbol{p}$-Value & R-Squared \\
\hline No & No & No & 4.870 & $6.10 \times 10^{-18}$ & 0.546 \\
Yes & No & No & 4.280 & $7.94 \times 10^{-22}$ & 0.660 \\
Yes & Yes & No & 0.516 & $7.48 \times 10^{-25}$ & 0.733 \\
Yes & Yes & Yes & 0.449 & $1.78 \times 10^{-28}$ & 0.809 \\
Yes & No & Yes & 3.110 & $1.93 \times 10^{-28}$ & 0.816 \\
\hline
\end{tabular}

\subsubsection{Multivariate Polynomial Regression Models}

Implemented on all three variables (i.e., high blood pressure, high cholesterol, and obesity) separately as dependent variables yielded the results. The multivariate polynomial model of the second degree, with "obesity" as the dependent variable, again attained 
the highest accuracy score of approximately $81 \%$. This was followed by the multivariate polynomial model of the second degree with "high blood pressure" as the dependent, scoring a slightly above $50 \%$. The accuracy for the multivariate polynomial model of the second degree, with "high blood pressure" as the dependent variable, was better than the accuracy obtained for the same variable modeled with multiple linear regression (which fell below 40\%). Figure 11 shows the predicted trend versus the test data. The peaks and troughs were very well in sync, using the multivariate polynomial regression for the obesity rate model. In addition, Figure 10 shows the R-Squared and RMSE comparison of multivariate polynomial regression based on second- and third-order polynomial functions. The performance of the model was quite similar in comparison.

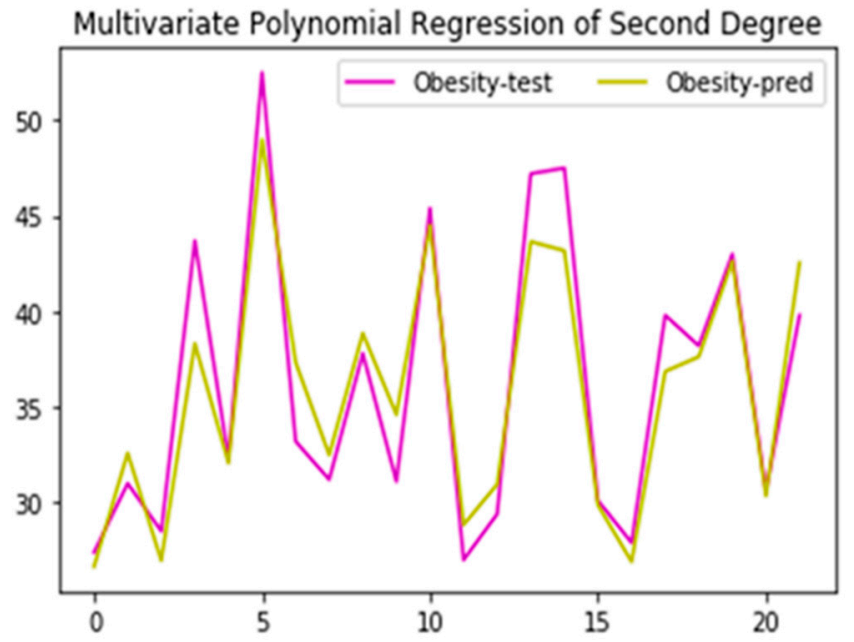

Figure 11. Multivariate polynomial regression of second degree.

\section{Conclusions and Future Research}

This research investigated the possibility of the geographic correlation of three health issues (i.e., high blood pressure, high cholesterol, and obesity) with food distribution and the statistical correlation with income and car access. These health issues were investigated together to provide a thorough analysis of the chronic health conditions in Guilford County. This study used geospatial technologies and machine learning techniques to provide insights into developing sustainable and healthy communities by examining the presence of food deserts, food swamps, and food oases. We demonstrated how access to healthy food options influenced health and mortality outcomes in one of the largest counties in the state of North Carolina, USA. Specifically, we co-intersected county-level data on representing food access, income distribution, and access to personal and public transportation with data on health or issues and mortality rates.

We started by showing the food outlets' density and health records in the county. The density measuring technique was an alternative method to creating food access maps. The RFEI measure showed only the quantitative index value and may not have covered all tracts based on the equation's requirements. Then, we analyzed the health records in the food desert, where people had limited access to healthy food options due to the low income and low transportation access. We also created geospatial maps of food swamps and food oases. Geospatial data presented the distribution of food deserts in Greensboro and Highpoint downtowns; high income distributes in the northwest of Greensboro, in Summerfield, Oakridge, and Kernersville; high density of food outlets, both healthy and unhealthy, in Greensboro and highpoint. The results clearly showed that food swamps had a higher density of unhealthy food outlets than healthy outlets, while a food oasis had a higher density of healthier than unhealthy food options. We then compared the health records in each of these food geographies to examine any influence of healthy food access on health issues. 
This study was limited to the study area of Guilford County. The county-level was practical for showing the current stage and helping local decision makers. Involving more counties for comparison would have supported the study's hypothesis that health issues had a positive correlation with food distribution.

The results of the GIS analysis demonstrated that food deserts with low income, high population density, and low access to transportation were less sustainable, as they showed a high correlation with severe health issues and mortality. Food swamps and oases showed lower health issues and mortality rates compared to food deserts due to the availability of transportation access and income higher than poverty in these areas. The food swamp was a better option than food desert because, nonetheless, the unhealthy food options were accessible. The study's results presented the correlation of food environment with three health issues, unlike other studies. For instance, a study analyzed the numbers of healthy and unhealthy foods and the rate of obesity and found a correlation with unhealthy food options [45]. However, our study investigated more variables, such as income and car access, which were parts of food access areas.

Food deserts showed greater health issues. This could be related to one of the area's characteristics: the availability of unhealthy food outlets, high poverty rates, and low access to transportation. Regarding the availability of unhealthy food, some studies showed no association between unhealthy food and health issues such as obesity and hypertension. A study applied statistical analysis to investigate the correlation between unhealthy food options and obesity and hypertension in children but found no significant correlation [46].

Regression models were used to detect relationships and predict results. The application of several regression models was objective in comparing their results. It illustrated the most correlated variables regarding health issues for inclusion in the development plan. Moreover, illustrating these strong variables would benefit stakeholders in directing new plans and investments. Multi-output regression and multiple linear regression analyses were used to examine the correlation between independent and dependent variables in the study area. Multi-output regression is a series of independent linear regressions. There are three outputs and three inputs. The linear regression for the multioutput model coefficients and intercepts is given in the table below (Table 8) and the parameters in Table 3. We included different regression models for comparison and evaluated the model with the highest performance. In machine learning, it is not always straightforward that a better model will consistently give higher performances across all distributions of a data set.

Table 8. Models' coefficients.

\begin{tabular}{ccccc}
\hline & & Coefficients & Intercept & \\
\hline Models & MedIncome & Car_Access & Population & \\
\hline High blood pressure & $-4.04 \times 10^{-5}$ & 7.72 & $-4.18 \times 10^{-4}$ & 35.64 \\
\hline High cholesterol & $3.79 \times 10^{-5}$ & 4.31 & $-7.89 \times 10^{-4}$ & 35.37 \\
\hline Obesity & -1.47 & 4.05 & $2.65 \times 10^{-4}$ & 41.44 \\
\hline
\end{tabular}

The obesity and high-cholesterol output variables showed high positive and negative correlations $\left(R^{2}=0.79\right.$ and -0.81$)$, respectively, based on the independent variables of low car access, population, and median income. The obesity and high cholesterol variables were modeled using random forest and decision trees for the above performance. In contrast, the linear and nonlinear regression models could only help to predict the dependent variable obesity with an $R^{2}$ value greater than 0.80 .

The correlation matrix results illustrated a strong, negative relationship between income and obesity and a positive relationship between independent variables, high blood pressure, and high cholesterol. In addition, it presented the correlation between obesity and income. There was more of a correlation of the independent variable with obesity than between high blood pressure and high cholesterol. 
Overall, our results suggested that when compared to food swamps and food oases, food deserts would be the most vulnerable and would probably experience the highest mortality rates in the case of health-related disasters. The presence of such food deserts challenges the sustainable community goals of city and county administrators and directs the need for development in these areas for better future planning.

Future studies may examine the long-term statistical association of food with respect to commercial and governmental policies implemented and its impact on people's health and conditions. More specific future studies may investigate the low rate of health issues in food swamp areas. Moreover, future research may investigate the increase in health issues and potential cause(s) in various areas over time and recommend possible solutions.

Author Contributions: Conceptualization, Abrar Almalki and Balakrishna Gokaraju; methodology; Abrar Almalki, Ba-lakrishna Gokaraju and Nikhil Mehta; validation, Abrar Almalki and Balakrishna Gokaraju; formal analysis, Abrar Almalki, Nikhil Mehta, and Balakrishna Gokaraju; resources, Balakrishna Gokaraju, Nikhil Mehta, and Abrar Almalki; data curation, Abrar Almalki; writing-original draft preparation, Abrar Almalki; writing-review and editing, Nikhil Mehta and Balakrishna Gokaraju; supervision, Balakrishna Gokaraju; funding acquisition; Abrar Almalki. Daniel Adrian Doss, emergency management subject expert; homeland security subject expert; draft manuscript preparation; English language; editing and revision; content advising. All authors have read and agreed to the published version of the manuscript.

Funding: This research is sponsored by the partial funding from North Carolina Department of Environmental Quality (NCDEQ) and NC CARES Act. 2020-21.

Data Availability Statement: Data, such as income and food access, were downloaded from the USDA Food Desert Locator Map website at https: / / www.ers.usda.gov/data-products/food-accessresearch-atlas / go-to-the-atlas.aspx (accessed on 18 November 2020).

Acknowledgments: We thank Mark Smith from the Health Department in Guilford County, Greensboro, NC, for providing the preliminary data sets on health statistical records and other data. The authors also sincerely acknowledge the Health Surveillance and Analysis Unit of the Guilford County Department of Health and Human Services, Division of Public Health, as a source as well as the NC Electronic Disease Surveillance System (NC EDSS) of NC DHHS for providing data sets. The authors would like to thank Marwan Bikdash, Chair of Dept. of Computational Data Science and Engineering in NCAT for supporting the publication cost of this manuscript.

Conflicts of Interest: The authors declare no conflict of interest.

\section{References}

1. Greensboro, High Point Top Nationwide Hunger List. News \& Record. 2021. Available online: https:/ /www.greensboro.com/ news/local_news/greensboro-high-point-top-nationwide-hunger-list/article_88828c52-e568-11e4-9b5b-db55afd7f635.html (accessed on 15 April 2021).

2. Neufeld, H.T.; Richmond, C.; Southwest Ontario Aboriginal Health Access Centre. Exploring First Nation Elder Women's Relationships with Food from Social, Ecological, and Historical Perspectives. Curr. Dev. Nutr. 2020, 4, nzaa011. [CrossRef]

3. Ohri-Vachaspati, P.; DeLia, D.; DeWeese, R.S.; Crespo, N.C.; Todd, M.; Yedidia, M.J. The relative contribution of layers of the Social Ecological Model to childhood obesity. Public Health Nutr. 2015, 18, 2055-2066. [CrossRef]

4. Dammhahn, M.; Kappeler, P.M. Females go where the food is: Does the socio-ecological model explain variation in social organisation of solitary foragers? Behav. Ecol. Sociobiol. 2009, 63, 939-952. [CrossRef]

5. Letaifa, S.B. How to strategize smart cities: Revealing the SMART model. J. Bus. Res. 2015, 68, 1414-1419. [CrossRef]

6. Widener, M.J.; Shannon, J. When are food deserts? Integrating time into research on food accessibility. Health Place 2014, 30, 1-3. [CrossRef]

7. Charreire, H.; Casey, R.; Salze, P.; Simon, C.; Chaix, B.; Banos, A.; Badariotti, D.; Weber, C.; Oppert, J.-M. Measuring the food environment using geographical information systems: A methodological review. Public Health Nutr. 2010, 13, $1773-1785$. [CrossRef]

8. Chang, K.-T. Geographic information system. Int. Encycl. Geogr. People Earth Environ. Technol. People Earth Environ. Technol. 2016, 1-9. [CrossRef]

9. Truong, K.; Fernandes, M.; An, R.; Shier, V.; Sturm, R. Measuring the physical food environment and its relationship with obesity: Evidence from California. Public Health 2010, 124, 115. [CrossRef] 
10. Brownlee, J. Difference between Algorithm and Model in Machine Learning. Machine Learning Mastery. 2021. Available online: https:/ / machinelearningmastery.com/difference-between-algorithm-and-model-in-machine-learning/ (accessed on 22 September 2021).

11. Alzubi, J.; Nayyar, A.; Kumar, A. Machine learning from theory to algorithms: An overview. J. Phys. Conf. Ser. 2018, $1142,012012$. [CrossRef]

12. Segal, M.R. Machine Learning Benchmarks and Random Forest Regression. 2004. Available online: https://escholarship.org/uc/ item/35x3v9t4 (accessed on 22 September 2021).

13. Mahmoudi, M.R. On comparing two dependent linear and nonlinear regression models. J. Test. Eval. 2018, 47, 449-458. [CrossRef]

14. Teixeira-Pinto, A. 2 K-Nearest Neighbours Regression I Machine Learning for Biostatistics. Bookdown.Org. 2021. Available online: https://bookdown.org/tpinto_home/Regression-and-Classification/k-nearest-neighbours-regression.html (accessed on 22 September 2021).

15. Westerveld, J.J.L.; van den Homberg, M.J.C.; Nobre, G.G.; van den Berg, D.L.J.; Teklesadik, A.D.; Stuit, S.M. Forecasting transitions in the state of food security with machine learning using transferable features. Sci. Total Environ. 2021, 786, 147366. [CrossRef]

16. Amin, M.D.; Badruddoza, S.; McCluskey, J.J. Predicting access to healthful food retailers with machine learning. Food Policy 2021, 99, 101985. [CrossRef]

17. Ahvenniemi, H.; Huovila, A.; Pinto-Seppä, I.; Airaksinen, M. What are the differences between sustainable and smart cities? Cities 2017, 60, 234-245. [CrossRef]

18. Statement of Policy, Healthy Food Access. NACCHO: Washington, DC, USA. Available online: https://www.naccho.org/ uploads/downloadable-resources/13-04-Healthy-Food-Access.pdf (accessed on 15 April 2021).

19. Hodgson, K. Planning for Food Access and Community-Based Food System. 2012. Available online: http:/ / citeseerx.ist.psu.edu/ viewdoc/download?doi=10.1.1.593.1056\&rep=rep1\&type=pdf (accessed on 22 September 2021).

20. Jin, H.; Lu, Y. Evaluating Consumer Nutrition Environment in Food Deserts and Food Swamps. Int. J. Environ. Res. Public Health 2021, 18, 2675. [CrossRef]

21. Kaufman, P.R. Rural poor have less access to supermarkets, large grocery stores. Rural Am. Rural Dev. Perspect. 1998, 13, 19-26.

22. Kuai, X.; Zhao, Q. Examining healthy food accessibility and disparity in Baton Rouge, Louisiana. Ann. GIS 2017, 23, 103-116. [CrossRef]

23. Frankel, L.K. The Relation of Life Insurance to Public Hygiene. Am. J. Public Hyg. 1910, $20,258$.

24. Abel, K.C.; Faust, K.M. Modeling complex human systems: An adaptable framework of urban food deserts. Sustain. Cities Soc. 2020, 52, 101795. [CrossRef]

25. Nica-Avram, G.; Harvey, J.; Smith, G.; Smith, A.; Goulding, J. Identifying food insecurity in food sharing networks via machine learning. J. Bus. Res. 2021, 131, 469-484. [CrossRef]

26. Walker, R.E.; Keane, C.R.; Burke, J.G. Disparities and access to healthy food in the United States: A review of food deserts literature. Health Place 2010, 16, 876-884. [CrossRef]

27. Stucker, H.; Parmenter, B. Multi-level Food Retail Opportunities: Improving food access in Boston's most underserved neighborhoods through grocery store development, small food market improvements, and mobile produce market stop expansion. Appl. Geogr. 2013, 31, 1216-1223.

28. Guy, C.M.; David, G. Measuring physical access to 'healthy foods' in areas of social deprivation: A case study in Cardiff. Int. J. Consum. Stud. 2004, 28, 222-234. [CrossRef]

29. Jeffery, R.W.; Baxter, J.; McGuire, M.; Linde, J. Are fast food restaurants an environmental risk factor for obesity? Int. J. Behav. Nutr. Phys. Act. 2006, 3, 1-6. [CrossRef]

30. Sisiopiku, V.P.; Barbour, N. Use of gis spatial analysis to identify food deserts in the state of alabama. Athens J. Health 2014, 1, 91-103. [CrossRef]

31. Cossman, R.E.; Cossman, J.S.; Jackson, R.; Cosby, A. Mapping high or low mortality places across time in the United States: A research note on a health visualization and analysis project. Health Place 2003, 9, 361-369. [CrossRef]

32. Gehlen, M.; Nicola, M.R.C.; Costa, E.R.D.; Cabral, V.K.; de Quadros, E.L.L.; Chaves, C.O.; Lahm, R.A.; Nicolella, A.D.R.; Rossetti, M.L.R.; Silva, D.R. Geospatial intelligence and health analitycs: Its application and utility in a city with high tuberculosis incidence in Brazil. J. Infect. Public Health 2019, 12, 681-689. [CrossRef]

33. Quiñones, S.; Goyal, A.; Ahmed, Z.U. Geographically weighted machine learning model for untangling spatial heterogeneity of type 2 diabetes mellitus (T2D) prevalence in the USA. Sci. Rep. 2021, 11, 1-13.

34. Black, C.; Moon, G.; Baird, J. Dietary inequalities: What is the evidence for the effect of the neighbourhood food environment? Health Place 2014, 27, 229-242. [CrossRef] [PubMed]

35. Obesity. 2021. Available online: https://www.who.int/westernpacific/health-topics/obesity (accessed on 21 September 2021).

36. High Cholesterol Facts. Centers for Disease Control and Prevention. 2021. Available online: https://www.cdc.gov/cholesterol/ facts.htm (accessed on 21 September 2021).

37. High Blood Pressure Symptoms, Causes, and Problems Cdc. Gov. Centers for Disease Control and Prevention. 2021. Available online: https: / / www.cdc.gov/bloodpressure/about.htm (accessed on 22 September 2021).

38. The Demographic Statistical Atlas of the United States-Statistical Atlas. Statisticalatlas. Com. 2021. Available online: https: / / statisticalatlas.com/county/North-Carolina/Guilford-County/Population (accessed on 10 May 2021). 
39. U.S. Census Bureau Quickfacts: Guilford County, North Carolina. Census Bureau Quickfacts. 2021. Available online: https: //www.census.gov/quickfacts/guilfordcountynorthcarolina (accessed on 10 May 2021).

40. Maulud, D.; Abdulazeez, A.M. A Review on Linear Regression Comprehensive in Machine Learning. J. Appl. Sci. Technol. Trends 2020, 1, 140-147. [CrossRef]

41. How Much You Have to Earn to Be Considered Middle Class in Every US State. Business Insider. 2021. Available online: https:/ / www.businessinsider.com/middle-class-in-every-us-state-2015-4 (accessed on 15 April 2021).

42. Dutko, P.; Ver Ploeg, M.; Farrigan, T. Characteristics and Influential Factors of Food Deserts. Economic Research Report Number 140. Washington D.C. USA. United States Department of Agriculture. 2012. Available online: https://www.ers.usda.gov/ webdocs / publications/45014/30940_err140.pdf (accessed on 21 September 2021).

43. Access to Healthy Food. Health Concern. Guilford County Department of Public Health Community Health Assessment. 2013. Available online: https://www.guilfordcountync.gov/home/showdocument?id=268\#: \{\}:text=Food $\% 20 \mathrm{deserts} \% 20$ are $\% 20$ defined $\% 20$ as $\% 20$ areas $\% 20$ where $\% 20$ at,high-poverty $\% 2 \mathrm{C} \% 20$ high-minority $\% 20$ areas $\% 20$ of $\% 20$ Greensboro $\% 20$ and $\%$ 20High\%20Point (accessed on 23 September 2021).

44. Green, D. Your Census Tract May Get You Lower Mortgage Rates. Mortgage Rates, Mortgage News and Strategy: The Mortgage Reports. 2021. Available online: https:/ / themortgagereports.com/18912/census-tract-low-income-high-minority-mortgagerates-homeready (accessed on 23 September 2021).

45. Morland, K.B.; Evenson, K.R. Obesity prevalence and the local food environment. Health Place 2009, 15, 491-495. [CrossRef]

46. Cummins, S.C.J. The local food environment and health: Some reflections from the United Kingdom. Am. J. Public Health 2003, 93, 521. [CrossRef] [PubMed] 